\title{
Gestational Weight Gain Influences the Adipokine-Oxidative Stress Association during Pregnancy
}

\author{
Juan Mario Solis Paredes ${ }^{a}$ Otilia Perichart Perera ${ }^{b}$ Araceli Montoya Estradac \\ Enrique Reyes Muñoz ${ }^{c}$ Salvador Espino y Sosa ${ }^{d}$ Veronica Ortega Castillo ${ }^{\mathrm{e}}$ \\ Diana Medina Bastidas ${ }^{f}$ Maricruz Tolentino Dolores ${ }^{b}$ \\ Maribel Sanchez Martinez ${ }^{g}$ Sonia Nava Salazar ${ }^{g}$ Guadalupe Estrada Gutierrez ${ }^{\text {h }}$ \\ ${ }^{a}$ Department of Human Genetics and Genomics, Instituto Nacional de Perinatologia, Mexico City, Mexico; ${ }^{b}$ Instituto \\ Nacional de Perinatologia, Nutrition and Bioprogramming Coordination, Mexico City, Mexico; ' Instituto Nacional de \\ Perinatologia, Coordination of Gynecological and Perinatal Endocrinology, Mexico City, Mexico; ${ }^{d}$ Instituto Nacional

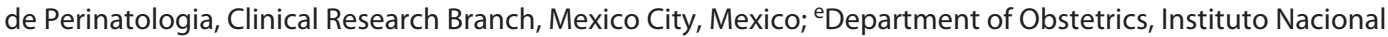 \\ de Perinatologia, Mexico City, Mexico; fInstituto Nacional de Perinatologia- Facultad de Quimica-UNAM, Unidad \\ de Investigación en Reproducción Humana, Mexico City, Mexico; 9 Department of Inmunobiochemistry, Instituto \\ Nacional de Perinatologia, Mexico City, Mexico; ${ }^{\text {h}}$ Research Division, Instituto Nacional de Perinatologia, Mexico City, \\ Mexico
}

\section{Keywords}

Gestational weight gain · Adipokines · Oxidative stress

\begin{abstract}
Introduction and Objective: The weight gained during pregnancy could determine the immediate and future health of the mother-child dyad. Excessive gestational weight gain (EGWG) due to abnormal adipose tissue (AT) accumulation is strongly associated with adverse perinatal outcomes as gestational diabetes, macrosomia, obesity, and hypertension further in life. Dysregulation of adipokine, AT dysfunction, and an imbalance in the prooxidant-antioxidant systems are critical features in altered AT accumulation. This study was aimed to investigate the association between adipokines and oxidative stress markers in pregnant women and the influence of the GWG on this association. Methods: Maternal blood samples were obtained in the third trimester
\end{abstract}

karger@karger.com www.karger.com/ofa

Karger $\stackrel{\text { ' }}{5}$

GOPEN ACCESS
(C) 2021 The Author(s)

Published by S. Karger AG, Basel

This is an Open Access article licensed under the Creative Commons Attribution-NonCommercial-4.0 International License (CC BY-NC) (http://www.karger.com/Services/OpenAccessLicense), applicable to the online version of the article only. Usage and distribution for commercial purposes requires written permission. of pregnancy ( $n=74)$ and serum adipokines (adiponectin, leptin, and resistin), oxidative damage markers: 8-oxo-2'deoxyguanosine (8-oxodG), lipohydroperoxides $(\mathrm{LOOH})$, malondialdehyde (MDA), and carbonylated proteins (CP), and glucose a metabolic marker were measured. Results: Women with EGWG had low adiponectin levels than women with adequate weight gain (AWG) or insufficient weight gain (IWG). Multiple linear regression models revealed a positive association between adiponectin and 8-oxodG in women with AWG ( $B=1.09,95 \% \mathrm{Cl}: 164-222, p=0.027)$ and IWG $(B=0.860,95 \% \mathrm{Cl}: 0.199-1.52, p=0.013)$ but not in women with EGWG. In women with EGWG, leptin was positively associated with LOOH $(p=0.018), \operatorname{MDA}(p=0.005)$, and CP $(p=0.010)$ oxidative markers. Conclusion: Our findings sug-

Juan Mario Solis-Paredes and Otilia Perichart-Perera contributed equally to this work. 
gest that concurrent mechanisms regulate adipokine production and oxidative stress in pregnant women and that this regulation is influenced by GWG, probably due to an excessive AT accumulation.

(C) 2021 The Author(s).

Published by S. Karger AG, Basel

\section{Introduction}

Pregnancy involves deep anatomical, physiological, and biochemical adaptations that are important to provide proper fetal nutrition [1-3]. These maternal changes begin after conception and affect different organs, the immune system, and diverse metabolic pathways [4]. Gestational weight gain (GWG) is a critical process to support adequate fetal growth and development and is defined as the amount of weight gained during pregnancy, which is composed by the fetus, placenta, uterus, amniotic fluid, and the increase in the maternal breast tissue, blood volume, and adipose tissue (AT) [5-7]. GWG varies greatly depending on factors such as prepregnancy weight and the body mass index (BMI) $[8,9]$.

An excessive GWG (EGWG) increases the risk of maternal and neonatal adverse outcomes such as preeclampsia, gestational diabetes, preterm labor, and fetal macrosomia [10-13]. In addition to increasing the immediate risk of gestational complications, it has been demonstrated that EGWG is associated with postpartum weight retention, with short- and long-term metabolic consequences for the mother [5-7]. The EGWG also generates an adverse intrauterine environment that affects fetal growth and is associated with increased rates of obesity and other cardiometabolic diseases in the offspring $[7,13$, 14], playing a key role in the metabolic programming of chronic diseases $[15,16]$. EGWG may be a sign of higher AT accretion during pregnancy $[6,7,13-16]$. An excessive fat mass gain appears to be playing a key role in the metabolic programming of chronic diseases $[15,16]$.

Excessive AT accumulation is characterized by dysregulation of adipokine release, including leptin, adiponectin, and resistin; particularly, excess of visceral AT (VAT) appears to play a more significant pathogenic role in the development of chronic metabolic diseases in adults [1720]. On the other hand, excessive AT generates an imbalance between the prooxidative - and antioxidative systems that usually results in a reactive oxygen species (ROS) increase [18, 21, 22]. While low ROS levels are essential to maintain diverse physiological functions, excessive ROS production alters different cellular components such as proteins, lipids, and DNA, generating oxidized biomolecules that function as biomarkers of oxidative damage. Elevation of malondialdehyde (MDA), carbonylated proteins (CP), and oxidized base 8-oxo- $2^{\prime}$ deoxyguanosine (8-oxodG) as indicators of lipid peroxidation, protein, and DNA oxidation, respectively carries deleterious effects on cells [18, 21-25].

Both adipokine dysregulation and oxidative stress damage are focal points in inflammation and metabolic dysfunction and have been related to pregnancy complications and fetal programming, turning them into potential biomarkers of adverse perinatal outcomes. In this context, we have previously demonstrated a close relationship between these metabolic markers with the pregestational maternal weight status and maternal age [26].

Considering the above, we hypothesized that GWG might lead to alterations in adipokine levels and oxidative damage. Therefore, this research was aimed to evaluate the association between serum adipokines and oxidative stress markers in women in the third trimester of pregnancy and the influence of the GWG status on this association.

\section{Methods}

\section{Research Design and Study Population}

This cross-sectional study was performed at the Instituto $\mathrm{Na}$ cional de Perinatologia in Mexico City and is a secondary analysis from the OBESO (epigenetic and biochemical origin of obesity) perinatal cohort. The project was approved by the Institutional Review Board (protocol number: 3300-11402-01-575-17). Participation was voluntary, and all women who agreed to participate signed the informed consent form. The study was conducted ethically in accordance with the World Medical Association Declaration of Helsinki.

For this analysis, we studied pregnant women in the third trimester of pregnancy, recruited between January 2018 and January 2019. Gestational age was calculated according to the fetal ultrasound performed in the first trimester of pregnancy. The sample was selected by convenience, according to the pregestational BMI $\left(\mathrm{p}\right.$-BMI $\left.\left[\mathrm{kg} / \mathrm{m}^{2}\right]\right)(\mathrm{p}-\mathrm{BMI}=18.5-24.9$ as normal weight, $\mathrm{p}$-BMI $\geq 25$ as overweight, and $\mathrm{p}-\mathrm{BMI} \geq 30$ as obesity), following the WHO guidelines [27]. All women meet the following inclusion criteria: adult women and singleton pregnancy; exclusion criteria included: multiple pregnancy, comorbidities (diabetes mellitus, renal or hepatic diseases, congenital malformations, autoimmune diseases, or uncontrolled thyroid disease), and taking any medication that may affect endocrine metabolism (insulin, metformin, and/or corticosteroids).

\section{Anthropometric and Biochemical Parameters}

Pregestational weight $(\mathrm{kg})$ was self-reported, and height $(\mathrm{cm})$ was measured with a stadiometer (SECA 220, Hamburg, Germany) by trained personnel. Pregestational weight and height were used to calculate p-BMI. GWG was calculated in the last clinical 
Table 1. Maternal characteristics, metabolic parameters, adipokine, and oxidative damage markers concentration according to the gestational weight gain (GWG) status

\begin{tabular}{llll}
\hline Variable & \multicolumn{2}{l}{ GWG status } & \\
\cline { 2 - 4 } & $\begin{array}{l}\text { insufficient } \\
(n=28)\end{array}$ & $\begin{array}{l}\text { adequate } \\
(n=20)\end{array}$ & $\begin{array}{l}\text { excessive } \\
(n=26)\end{array}$ \\
\hline Age, years & $30.2 \pm 1.61$ & $31.1 \pm 1.73$ & $29.8 \pm 1.69$ \\
p-BMl, kg/m & $27.3 \pm 1.22$ & $27.6 \pm 1.26$ & $28.8 \pm 1.18$ \\
p-BMI status, $n$ (\%) & & & \\
$\quad$ Normal & $12(42.9)$ & $9(45.0)$ & $6(23.1)$ \\
$\quad$ Overweight or obese & $16(57.1)$ & $11(55.0)$ & $20(76.9)$ \\
GWG, kg & $5.38 \pm 0.64$ & $9.21 \pm 0.73^{\mathrm{a}}$ & $14.8 \pm 0.68^{\mathrm{b}, \mathrm{c}}$ \\
GA at sampling, weeks & $35.0 \pm 0.62$ & $34.6 \pm 0.77$ & $35.6 \pm 0.56$ \\
Fasting glucose, mg/dL & $82.0 \pm 2.36$ & $84.6 \pm 3.72$ & $83.2 \pm 2.62$ \\
Adiponectin, $\mu \mathrm{mg} / \mathrm{mL}$ & $14.8 \pm 2.04$ & $15.0 \pm 2.56$ & $7.69 \pm 1.21^{\mathrm{b}, \mathrm{c}}$ \\
Leptin, ng/mL & $23.2 \pm 3.29$ & $36.0 \pm 7.22$ & $39.4 \pm 8.78$ \\
Resistin, ng/mL & $20.2 \pm 1.76$ & $21.1 \pm 2.83$ & $19.9 \pm 2.15$ \\
LOOH, pmol I/mg dry weight & $28.4 \pm 1.97$ & $25.1 \pm 1.63$ & $28.8 \pm 2.53$ \\
MDA, pmol MDA/mg dry weight & $156 \pm 14.9$ & $136 \pm 15.9$ & $156 \pm 14.6$ \\
CP, nmol CP/mg protein & $12.3 \pm 0.78$ & $12.3 \pm 0.93$ & $12.3 \pm 0.84$ \\
8-oxodG, ng/mL & $195 \pm 4.52$ & $200 \pm 5.28$ & $186 \pm 4.50$ \\
\hline
\end{tabular}

Values represent mean \pm SEM. One-way ANOVA with the minimum significant difference post hoc test. ${ }^{\mathrm{a}} p<0.05$ adequate versus insufficient. ${ }^{\mathrm{b}} p<0.05$ excessive versus adequate. c $p<0.05$ excessive versus insufficient. $\mathrm{p}$-BMI, pregestational body mass index; GA, gestational age; $\mathrm{LOOH}$, lipohydroperoxides; MDA, malondialdehyde; $\mathrm{CP}$, carbonylated proteins; 8-oxodG, 8-oxo-2'-deoxyguanosine. visit at the third trimester and women were categorized according to IOM 2009 guidelines [28] as adequate weight gain (AWG), insufficient weight gain (IWG), and excessive weight gain (EWG) for their specific gestational age.

\section{Samples}

Fasting maternal venous blood samples were drawn in Vacutainer tubes (Becton-Dickinson, Franklin Lakes, NJ, USA) and centrifuged at $4^{\circ} \mathrm{C}$ for $15 \mathrm{~min}$ at $1,000 \mathrm{~g}$. Serum samples were stored at $-70^{\circ} \mathrm{C}$ until the assays were performed.

\section{Biochemical Analysis}

Fasting serum glucose concentrations were measured by enzymatic colorimetric methods using an automated analyzer (ISE Echo Lory 2000) and commercial kits (DiaSys Diagnostic Systems $\mathrm{GmbH}$, Germany).

\section{Adipokines}

ELISA commercial kits to measure serum adiponectin (DY1065), leptin (DY398), and resistin (DY1359) (R\&D Systems Inc., Minneapolis, MN, USA) were used according to the manufacturer's instructions and read at $450 \mathrm{~nm}$ in a Synergy HT plate reader (BioTek, Winooski, VT, USA).

\section{Oxidative Stress Markers}

Serum 8-oxodG was measured to evaluate DNA oxidative damage using a commercial ELISA kit (4380-096-K) (TREVIGEN, Gaithersburg, MD, USA). Oxidative lipid damage was assessed by quantifying lipohydroperoxides (LOOH) [29] and MDA [30], as previously reported. Protein oxidative damage was evaluated by measuring the carbonyl group content [31].

\section{Statistical Analysis}

Descriptive statistics were used for data distribution and frequencies, and one-way ANOVA with the minimum significant difference post hoc test was used to analyze differences by GWG categories (AWG, IWG, or EWG). Data were expressed as mean \pm SEM, and $p$ values $<0.05$ were considered statistically significant. Spearman correlations were performed to study the correlation between adipokines and oxidative damage markers. Multiple linear regression models were done to investigate associations between adipokines and oxidative damage markers. Models were stratified by GWG categories. Statistics were performed using SPSS software (version 22, SPSS Statistics/IBM Corp., Armonk, NY, USA).

\section{Results}

Seventy-four women in the third trimester of pregnancy were studied. The mean age was $30.3 \pm 0.96$ years old, and the mean gestational age was $35.2 \pm 0.37$ weeks of gestation. Before pregnancy, $71.1 \%(n=47)$ of women were overweight or had obesity. According to GWG, $37.8 \%(n=28)$ had IWG and 35.2\% $(n=26)$ had EWG. Maternal anthropometric and metabolic parameters, ad- 
Table 2. Effect of adipokines on $\mathrm{LOOH}$ levels in pregnant women according to gestational weight gain
Table 3. Effect of adipokines on MDA levels in pregnant women according to gestational weight gain

\begin{tabular}{lllll}
\hline & $B$ & $95 \% \mathrm{Cl}$ & $p$ value & $R^{2} /\left(R^{2}\right.$ adjusted $)$ \\
\hline AWG & & & & \\
$\quad$ Constant & 32.3 & $21.5-43.1$ & $<\mathbf{0 . 0 0 0 1}$ & \\
$\quad$ Adiponectin & -0.169 & -0.496 to 0.157 & 0.288 & $0.147(-0.13)$ \\
$\quad$ Leptin & -0.028 & -0.147 to 0.092 & 0.631 & \\
$\quad$ Resistin & -0.171 & -0.461 to 0.119 & 0.229 & \\
IWG & & & & \\
Constant & 42.5 & $31.5-53.5$ & $<\mathbf{0 . 0 0 0 1}$ & \\
$\quad$ Adiponectin & -0.293 & -0.646 to 0.059 & 0.099 & $0.274(0.179)$ \\
Leptin & -0.167 & -0.393 to 0.058 & 0.139 & \\
$\quad$ Resistin & -0.270 & -0.674 to 0.134 & 0.180 & \\
EWG & & & & \\
$\quad$ Constant & 33.0 & $20.3-45.7$ & $\mathbf{0 . 0 0 0 1}$ & \\
Adiponectin & -0.220 & -1.04 to 0.602 & 0.471 & $0.438(0.349)$ \\
Leptin & 0.145 & $0.036-0.254$ & $\mathbf{0 . 0 1 2}$ & \\
$\quad$ Resistin & -0.423 & -0.841 to -0.006 & $\mathbf{0 . 0 4 7}$ & \\
\hline
\end{tabular}

Models included 74 pregnant women; adequate weight gain (AWG) $(n=20)$, insufficient weight gain (IWG) $(n=28)$, and excessive weight gain (EWG) $(n=26)$. LOOH, lipohydroperoxides.

\begin{tabular}{lllll}
\hline & $B$ & $95 \%$ Cl & $p$ value & $R^{2} /\left(R^{2}\right.$ adjusted $)$ \\
\hline AWG & & & & \\
$\quad$ Constant & 102 & $2.48-202$ & $\mathbf{0 . 0 4 5}$ & \\
$\quad$ Adiponectin & 1.85 & -1.16 to 4.86 & 0.211 & $0.233(0.090)$ \\
$\quad$ Leptin & 0.836 & -0.264 to 1.94 & 0.127 & \\
$\quad$ Resistin & -1.15 & -3.83 to 1.52 & 0.375 & \\
IWG & & & & \\
Constant & 257 & $176-339$ & $<\mathbf{0 . 0 0 0 1}$ & \\
$\quad$ Adiponectin & -1.10 & -3.73 to 1.53 & 0.398 & $0.302(0.211)$ \\
$\quad$ Leptin & -2.15 & -3.83 to -0.466 & $\mathbf{0 . 0 1 5}$ & \\
$\quad$ Resistin & -1.60 & -4.61 to 1.41 & 0.283 & \\
EWG & & & & \\
$\quad$ Constant & 164 & $94.0-235$ & $<0.0001$ & \\
Adiponectin & 0.996 & -3.65 to 5.64 & 0.659 & $0.435(0.350)$ \\
Leptin & 0.956 & $0.345-1.57$ & $\mathbf{0 . 0 0 4}$ & \\
$\quad$ Resistin & -2.42 & -4.80 to 0.044 & $\mathbf{0 . 0 4 6}$ & \\
\hline
\end{tabular}

Models included 74 pregnant women; adequate weight gain (AWG) $(n=20)$, insufficient weight gain (IWG) $(n=28)$, and excessive weight gain (EWG) $(n=26)$. MDA, malondialdehyde. ipokine levels, and oxidative damage markers according to GWG are summarized in Table 1. No differences were observed in maternal characteristics when stratified by GWG. Women with EWG had significantly lower concentrations of adiponectin than women with AWG ( $p=$ $0.016)$ and IWG $(p=0.010)$, showing a trend toward higher leptin levels $(p=0.080)$ than IWG. Also, women with EWG showed a trend of lower levels of 8-oxodG ( $p$ $=0.059)$ than AWG women. There were no differences in resistin, $\mathrm{LOOH}, \mathrm{MDA}$, and $\mathrm{CP}$ concentrations between EWG and AWG or IWG.

Spearman correlation analysis between adipokines and oxidative damage markers revealed a positive significant correlation between adiponectin and 8-oxodG concentration $(r=0.401 ; p=0.001)$ and inverse significant correlations with LOOH $(r=-0.262 ; p=0.027)$ and CP $(r=-0.237 ; p=0.046)$. Resistin was inversely correlated with LOOH $(r=-0.303 ; p=0.009)$ and MDA $(r=-0.256$; 
Table 4. Effect of adipokines on CP levels in pregnant women according to gestational weight gain
Table 5. Effect of adipokines on 8-oxodG levels in pregnant women according to gestational weight gain

\begin{tabular}{lllll}
\hline & $B$ & $95 \% \mathrm{Cl}$ & $p$ value & $R^{2} /\left(R^{2}\right.$ adjusted $)$ \\
\hline AWG & & & & \\
$\quad$ Constant & 12.4 & $6.32-18.4$ & $\mathbf{0 . 0 0 1}$ & \\
$\quad$ Adiponectin & -0.006 & -0.189 to 0.176 & 0.942 & $0.166(0.010)$ \\
$\quad$ Leptin & 0.039 & -0.028 to 0.106 & 0.234 & \\
$\quad$ Resistin & -0.067 & -0.229 to 0.095 & 0.393 & \\
IWG & & & & \\
$\quad$ Constant & 16.4 & $11.6-21.1$ & $<\mathbf{0 . 0 0 0 1}$ & \\
$\quad$ Adiponectin & -0.071 & -0.223 to 0.081 & 0.346 & $0.172(0.064)$ \\
$\quad$ Leptin & -0.076 & -0.173 to 0.022 & 0.121 & \\
$\quad$ Resistin & -0.063 & -0.238 to 0.111 & 0.238 & \\
EWG & & & & \\
$\quad$ Constant & 11.8 & $7.55-16.1$ & $<0.0001$ & \\
$\quad$ Adiponectin & -0.041 & -0.318 to 0.236 & 0.761 & $0.367(0.267)$ \\
Leptin & 0.053 & $0.016-0.089$ & $\mathbf{0 . 0 1 6}$ & \\
$\quad$ Resistin & -0.049 & -0.189 to 0.092 & 0.475 & \\
\hline
\end{tabular}

Models included 74 pregnant women; adequate weight gain (AWG) $(n=20)$, insufficient weight gain (IWG) $(n=28)$, and excessive weight gain (EWG) $(n=26) . \mathrm{CP}$, carbonylated proteins.

\begin{tabular}{lllll}
\hline & $B$ & $95 \% \mathrm{Cl}$ & $p$ value & $R^{2} /\left(R^{2}\right.$ adjusted $)$ \\
\hline AWG & & & & \\
$\quad$ Constant & 193 & $164-222$ & $<\mathbf{0 . 0 0 0 1}$ & \\
$\quad$ Adiponectin & 1.09 & $0.222-1.95$ & $\mathbf{0 . 0 2 7}$ & $0.365(0.246)$ \\
$\quad$ Leptin & 0.015 & -0.301 to 0.330 & 0.922 & \\
$\quad$ Resistin & -0.485 & -1.25 to 0.281 & 0.198 & \\
IWG & & & & \\
$\quad$ Constant & 164 & $141-187$ & $<\mathbf{0 . 0 0 0 1}$ & \\
Adiponectin & 0.860 & $0.199-1.52$ & $\mathbf{0 . 0 1 3}$ & $0.404(0.318)$ \\
Leptin & -0.097 & -0.544 to 0.350 & 0.657 & \\
$\quad$ Resistin & 0.867 & $0.066-1.67$ & $\mathbf{0 . 0 3 5}$ & \\
EWG & & & & \\
$\quad$ Constant & 190 & $168-211$ & $<\mathbf{0 . 0 0 0 1}$ & \\
Adiponectin & 1.04 & -0.408 to 2.49 & 0.149 & $0.235(0.121)$ \\
Leptin & -0.142 & -0.33 to 0.049 & 0.137 & \\
Resistin & -0.121 & -0.862 to 0.620 & 0.737 & \\
\hline
\end{tabular}

Models included 74 pregnant women; adequate weight gain (AWG) $(n=20)$, insufficient weight gain (IWG) $(n=28)$, and excessive weight gain (EWG) women ( $n=26)$. 8-oxodG, 8-oxo-2'-deoxyguanosine.

$p=0.028)$, as well as 8-oxodG with LOOH $(r=-0.343 ; p$ $=0.003)$.

Multiple linear regression models were performed to evaluate the association of adipokines and oxidative damage markers, according to GWG. In women with EWG, a significant positive association was observed between leptin and $\mathrm{LOOH}(B=0.145 ; 95 \% \mathrm{CI}=0.036-0.254 ; p=$ 0.012) (Table 2), MDA ( $B=0.956 ; 95 \% \mathrm{CI}=0.345-1.57$; $p=0.004)$ (Table 3$)$ and $\mathrm{CP}(B=0.053 ; 95 \% \mathrm{CI}=0.016$ $0.089 ; p=0.016$ ) (Table 4 ), and a negative association was observed between resistin and $\mathrm{LOOH}(B=-0.423$; $95 \%$ $\mathrm{CI}=-0.841$ to $-0.006 ; p=0.047)$ (Table 2$)$ and MDA $(B$ $=-2.42 ; 95 \% \mathrm{CI}=-4.80$ to $0.044 ; p=0.046)$ (Table 3 ).

Women with IWG presented a negative association between leptin and MDA ( $B=-2.15 ; 95 \% \mathrm{CI}=-3.83$ to $-0.466 ; p=0.015$ ) (Table 3 ). A positive association be- 
tween adiponectin and 8-oxodG was observed in women with AWG $(B=1.09,95 \%$ CI: $0.222-1.95, p=0.027)$ and IWG $(B=0.860,95 \%$ CI: $0.199-1.52, p=0.013)$ but not in women with EWG. In women with IWG, a positive association was also observed between resistin and 8-oxodG $(B=0.867,95 \%$ CI: 0.066-1.67, $p=0.035)$ (Table 5).

\section{Discussion}

In this study, we are providing novel evidence that adiponectin and 8-oxodG concentrations in women with AWG and IWG are positively correlated, while in women with EWG, this association is not observed. Adiponectin is secreted by adipocytes and it is involved in multiple functions as insulin sensitizing, stimulation of lipid metabolism, and glucose uptake, displaying anti-inflammatory properties, and correlating inversely with body weight and fat mass $[19,32-34]$. During pregnancy, adiponectin concentration drops due to an increase in fat mass, and it has been negatively correlated with birth weight, suggesting that adiponectin may be involved in placental nutrient transport $[35,36]$.

Although no differences were found in 8-oxodG levels among the groups, this marker showed a trend to be lower in EWG than AWG women. 8-oxodG has been classically studied as the most common base modification produced in DNA by oxidative damage, as a separate molecule, 8-oxodG exhibits protective functions [37]. 8-oxodG inactivates Rac1 and Rac2 proteins, inhibiting Rac-linked functions such as ROS production, controlling oxidative stress damage [38]. Besides the antioxidant activity, 8-oxodG displays anti-inflammatory properties, reducing the transcription of pro-inflammatory cytokines as TNF-, IL- $1 \beta$, IL- 6 , and IFN- $\gamma[37,38]$. In an obese mice model, the administration of 8-oxodG induces elevation of serum adiponectin, improves hyperglycemia and lipid profile, and diminishes the concentration of the pro-inflammatory cytokines TNF- $\alpha$ and IL- 6 , ameliorating the hallmarks of metabolic syndrome, including insulin resistance [39]. Thus, the positive association between 8-oxodG and adiponectin in women with AWG and IWG could indicate an adequate inflammatory oxidative stress balance, which is disrupted in pregnant women with EWG. This is in accord with our findings that adiponectin concentrations are higher in AWG and IWG women than women with EWG, correlating negatively with $\mathrm{LOOH}$ and MDA concentrations. In light of these observations, our data suggest that EWG, as an indicator of excessive fat mass accretion, appears to be involved in

Adipokines, Oxidative Stress Markers, and Gestational Weight Gain Association downregulation of adiponectin and could be related to a decreased ability to regulate oxidative damage, promoting the development of insulin resistance, gestational diabetes, preeclampsia, and placental dysfunction [40-42].

Leptin is secreted by AT and placenta and participates in regulating food intake, energy homeostasis, insulin secretion, as well as transport of nutrients to the fetus, correlating with p-BMI and adiposity [32, 43, 44]. In our study, women with EWG showed a tendency to higher leptin levels than the AWG group ( $p=0.087)$, which is probably related to abnormal accumulation of body fat. Accordingly, several studies have reported that high leptin levels in the 2 nd and 3rd trimester of pregnancy correlate with EWG [35, 45-47]. In contrast, PatroMałysza et al. [48] did not find differences in leptin concentration after delivery between AWG and EWG women.

Physiologically, pregnant women experience an increase in AT, mainly VAT [49]. During a persistent positive energy balance, VAT is increased due to adipocyte hypertrophy, leading to adipocyte dysfunction [50], and altered adipokine profiles, where adiponectin decreases and leptin concentration increases [51]. As far as we know, our study shows for the first time a positive association between leptin concentration and $\mathrm{LOOH}, \mathrm{MDA}$, and CP markers in pregnant women with EWG. Studies not associated with GWG or pregnancy have showed that high leptin levels induce ROS production, increasing lipid peroxidation, and protein carbonylation $[40,52,53]$. Interestingly, in our study, women with IWG showed a negative association between leptin and MDA concentrations, possibly related to VAT hypertrophy or less accumulation of this tissue.

Another interesting finding was the association between resistin and 8-oxodG in women with IWG that was not observed in AWG and EWG groups; as far as we know, no studies are reporting this association. Resistin is expressed in several tissues besides AT such as placenta and fetal membranes $[54,55]$. The effect of GWG on resistin levels remains unknown; in our study, we did not find differences in resistin levels between the groups but we are demonstrating an inverse association with $\mathrm{LOOH}$ and MDA concentrations.

It has been demonstrated that oxidative stress may be related to resistin decrease; 3T3-L1 cells exposed to low levels of $\mathrm{H}_{2} \mathrm{O}_{2}$ for a long time showed impaired resistin expression [56]. Very few studies have reported associations between resistin and oxidative damage markers with discrepant results. In N2a cells used as an Alzheimer model disease, resistin exerts a protective effect against neurotox- 
icity of amyloid- $\beta$ peptides, through the regulation of ROS levels and mitochondrial function [57]; however, other study showed a negative correlation between serum resistin and oxidative damage in normal weight individuals [58]. On the other hand, resistin may lead to the overproduction of ROS, generating oxidative stress by mitochondrial damage [59]. The protective effect of several adipokines against oxidative damage occurs through the interaction with their receptor in the cell membrane, triggering the transduction of signals involved in antioxidant defense. In the case of resistin, its receptor or receptors involved in antioxidant function have not been fully identified, and further research is required to understand if resistin is involved in oxidative damage control during pregnancy.

Pregnancy carries oxidative stress with increasing circulating ROS due to maternal physiological changes, which is counteracted by the synthesis of antioxidants [60]. Oxidative stress is caused by an imbalance between prooxidants secretion and antioxidant capacity and is a crucial factor in the pathophysiology of various pregnancy complications (i.e., preeclampsia and gestational diabetes mellitus) [61]. In this work, we studied if GWG modifies the three levels of oxidative damage to biomolecules: lipids, proteins, and DNA. Our results did not show any differences in oxidative damage markers ( $\mathrm{LOOH}, \mathrm{MDA}$, and $\mathrm{CP}$ ) between the study groups and as far as we know there are no studies to compare our findings. Since pregestational obesity is known to be a factor of oxidative stress [26], ongoing work in our lab is focused on elucidating whether pregnancy complicated with obesity and EGWG could represent an increased risk of oxidative damage.

This study has some limitations that should be addressed. Given the inability to weigh women before pregnancy, we used self-reported p-BMI, which may introduce bias in the classification of GWG. The sample size is relatively small and women were highly selected; therefore, results may not apply to all pregnant women. Variability may be an issue even though it was decreased by selecting study groups based on the p-BMI status.

\section{Conclusion}

Our findings suggest that concurrent mechanisms regulate adipokine production and oxidative stress in pregnant women and that this regulation is influenced by the GWG status, probably due to an excessive fat mass accumulation. As recommended by the Institute of Medicine [28], future work should be focused on the mechanisms that underlie the effects of GWG on the mother-baby dyad, which may result in adverse metabolic consequences later in life.

\section{Statement of Ethics}

The study was conducted ethically in accordance with the World Medical Association Declaration of Helsinki. The project was approved by the Institutional Review Board of Instituto $\mathrm{Na}$ cional de Perinatologia (protocol number: 3300-11402-01-57517). Participation was voluntary, and all women who agreed to participate signed the informed consent form.

\section{Conflict of Interest Statement}

The authors have no conflicts of interest to declare.

\section{Funding Sources}

This study was funded by Instituto Nacional de Perinatologia (grant numbers: 3300-11402-01-575-17 and 212250-08311), Consejo Nacional de Ciencia y Tecnologia (CONACyT) (grant number: 86840), Fondo Sectorial de Investigacion en Salud y Seguridad Social (FOSISS) (grant number: 2015-3-2-61661), and Fundación Mexicana para la Salud.

\section{Author Contributions}

G.E.-G., J.M.S.-P., and O.P.-P. designed the study; S. E.-S., O.P.-P., and J.M.S.-P. did statistical analysis; J.M.S.-P., A.M.-E., S.N.-S., M.S.-M., V.O.-C., and M.T.-D did methodology; G.E.-G., J.M.S.-P., S. E.-S., A.M.-E., E.R.-M., and O.P.-P. participated in data interpretation; J.M.S.-P. and D.M.-B. wrote the manuscript; and G.E.-G, O.P.-P., and E.R.-M did review the manuscript. All authors read and approved the final manuscript.

\section{Data Availability Statement}

All data that support the findings of this study are available from the corresponding author (Guadalupe Estrada-Gutierrez) on reasonable request.

\section{References}

1 Newton ER, May L. Adaptation of maternalfetal physiology to exercise in pregnancy: the basis of guidelines for physical activity in pregnancy. Clin Med Insights Womens Health. 2017 Feb 23;10:1179562X17693224.

2 Soma-Pillay P, Nelson-Piercy C, Tolppanen $\mathrm{H}$, Mebazaa A. Physiological changes in pregnancy. Cardiovasc J Afr. 2016 Mar;27(2):8994. 
3 Moya J, Phillips L, Sanford J, Wooton M, Gregg A, Schuda L. A review of physiological and behavioral changes during pregnancy and lactation: potential exposure factors and data gaps. J Expo Sci Environ Epidemiol. 2014 Sep;24(5):449-58.

4 de Haas S, Ghossein-Doha C, van Kuijk SM, van Drongelen J, Spaanderman ME. Physiological adaptation of maternal plasma volume during pregnancy: a systematic review and meta-analysis. Ultrasound Obstet Gynecol. 2017 Feb;49(2):177-87.

5 Kominiarek MA, Peaceman AM. Gestational weight gain. Am J Obstet Gynecol. 2017 Dec; 217(6):642-51.

6 Gilmore LA, Klempel-Donchenko M, Redman LM. Pregnancy as a window to future health: excessive gestational weight gain and obesity. Semin Perinatol. 2015 Jun;39(4):296303.

7 Rifas-Shiman SL, Fleisch A, Hivert MF, Mantzoros C, Gillman MW, Oken E. First and second trimester gestational weight gains are most strongly associated with cord blood levels of hormones at delivery important for glycemic control and somatic growth. Metabolism. 2017 Apr;69:112-9.

8 Martin H, Thevenet-Morrison K, Dozier A. Maternal pre-pregnancy body mass index, gestational weight gain and breastfeeding outcomes: a cross-sectional analysis. BMC Pregnancy Childbirth. 2020 Aug 17;20(1): 471.

9 Sun Y, Shen Z, Zhan Y, Wang Y, Ma S, Zhang $S$, et al. Effects of pre-pregnancy body mass index and gestational weight gain on maternal and infant complications. BMC Pregnancy Childbirth. 2020 Jul 6;20(1):390.

10 Herrera TT, Garcia JL, Britton GB. Bloodbased biomarkers of adverse perinatal outcomes in maternal obesity. J Matern Fetal Neonatal Med. 2017 Dec;30(24):2991-7.

11 Santangeli L, Sattar N, Huda SS. Impact of maternal obesity on perinatal and childhood outcomes. Best Pract Res Clin Obstet Gynaecol. 2015 Apr;29(3):438-48.

12 Mission JF, Marshall NE, Caughey AB . Pregnancy risks associated with obesity. Obstet Gynecol. 2015:335-53.

13 McDowell M, Cain MA, Brumley J. Excessive gestational weight gain. J Midwifery Womens Health. 2019 Jan;64(1):46-54.

14 Liang Z, Liu H, Wang L, Chen Y, Zhou T, Heianza Y, et al. Maternal MTNR1B genotype, maternal gestational weight gain, and childhood obesity. Am J Clin Nutr. 2020 Feb 1; 111(2):360-8.

15 Barisic T, Mandic V, Barac I. Associations of body mass index and gestational weight gain with term pregnancy outcomes. Mater Sociomed. 2017 Mar;29(1):52-7.

16 Lecoutre S, Deracinois B, Laborie C, Eberlé D, Guinez C, Panchenko PE, et al. Depot- and sex-specific effects of maternal obesity in offspring's adipose tissue. J Endocrinol. 2016; 230:39-53.
17 Houshmand-Oeregaard A, Hansen NS, Hjort L, Kelstrup L, Broholm C, Mathiesen ER, et al. Differential adipokine DNA methylation and gene expression in subcutaneous adipose tissue from adult offspring of women with diabetes in pregnancy. Clin Epigenetics. 2017 Apr 13;9:37.

18 Manna P, Jain SK. Obesity, oxidative stress, adipose tissue dysfunction, and the associated health risks: causes and therapeutic strategies. Metab Syndr Relat Disord. 2015 Dec;13(10): 423-44.

19 Perichart-Perera O, Muñoz-Manrique C, Reyes-López A, Tolentino-Dolores M, Espino Y Sosa S, Ramírez-González MC, et al. Metabolic markers during pregnancy and their association with maternal and newborn weight status. PLoS One. 2017 Jul 27;12(7):e0180874.

20 Luo L, Liu M. Adipose tissue in control of metabolism. J Endocrinol. 2016;231:R77-99.

21 McMurray F, Patten DA, Harper ME. Reactive oxygen species and oxidative stress in obesity-recent findings and empirical approaches. Obesity. 2016;24:2301-10.

22 Marseglia L, Manti S, D’Angelo G, Nicotera A, Parisi E, Di Rosa G, et al. Oxidative stress in obesity: a critical component in human diseases. Int J Mol Sci. 2014;16:378-400.

23 Malti N, Merzouk H, Merzouk SA, Loukidi B, Karaouzene N, Malti A, et al. Oxidative stress and maternal obesity: feto-placental unit interaction. Placenta. 2014 Jun;35(6):411-6.

24 Jacob KD, Noren Hooten N, Trzeciak AR, Evans MK. Markers of oxidant stress that are clinically relevant in aging and age-related disease. Mech Ageing Dev. 2013 Mar;134(34):139-57.

25 Kim MH, Kim JY, Kim J-H, Lee H-S, Huh J-W, Lee D-S. Peroxiredoxin 2 deficiency reduces white adipogenesis due to the excessive ROS generation. Cell Biol Int. 2020 Jul 8.

26 Solis-Paredes M, Estrada-Gutierrez G, Perichart-Perera O, Montoya-Estrada A, Guzmán-Huerta M, Borboa-Olivares H, et al. Key clinical factors predicting adipokine and oxidative stress marker concentrations among normal, overweight and obese pregnant women using artificial neural networks. Int J Mol Sci. 2017 Dec 28;19(1).

27 Ferro-Luzzi A, Garza C, Haas J, Habicht JP, Himes J, Pradilla A, et al. Physical status: the use and interpretation of anthropometry. Report of a WHO Expert Committee. World Health Organ Tech Rep Ser. 1995;854:1-452.

28 Institute of Medicine (US) and National Research Council (US) Committee to Reexamine IOM Pregnancy Weight Guidelines. Weight gain during pregnancy: reexamining the guidelines. Washington (DC): National Academies Press (US); 2010.

29 el-Saadani M, Esterbauer H, el-Sayed M, Goher M, Nassar AY, Jürgens G. A spectrophotometric assay for lipid peroxides in serum lipoproteins using a commercially available reagent. J Lipid Res. 1989 Apr; 30(4):627-30.
30 Gérard-Monnier D, Erdelmeier I, Régnard K, Moze-Henry N, Yadan JC, Chaudière J. Reactions of 1-methyl-2-phenylindole with malondialdehyde and 4-hydroxyalkenals. Analytical applications to a colorimetric assay of lipid peroxidation. Chem Res Toxicol. 1998 Oct; 11(10):1176-83.

31 Dalle-Donne I, Rossi R, Giustarini D, Milzani A, Colombo R. Protein carbonyl groups as biomarkers of oxidative stress. Clin Chim Acta. 2003;329:23-38.

32 Poniedziałek-Czajkowska E, Mierzyński R, Słodzińska M, Dłuski D, LeszczyńskaGorzelak B. Adipokines and C-peptide in overweight and obese pregnant women. Ginekol Pol. 2018;89(8):442-8.

33 Lekva T, Roland MCP, Michelsen AE, Friis CM, Aukrust P, Bollerslev J, et al. Large reduction in adiponectin during pregnancy is associated with large-for-gestational-age newborns. J Clin Endocrinol Metab. 2017 Jul 1; 102(7):2552-9.

34 Kuryszko J, Sławuta P, Sapikowski G. Secretory function of adipose tissue. Pol J Vet Sci. 2016;19:441-6.

35 Mazurek D, Bronkowska M. Maternal anthropometric factors and circulating adipokines as predictors of birth weight and length. Int J Environ Res Public Health. 2020 Jul 3; 17(13):4799.

36 Aye IL, Powell TL, Jansson T. Review: adiponectin the missing link between maternal adiposity, placental transport and fetal growth? Placenta. 2013 Mar;34(Suppl 1):S40-5.

37 Kim DH, Cho IH, Kim HS, Jung JE, Kim JE, Lee $\mathrm{KH}$, et al. Anti-inflammatory effects of 8-hydroxydeoxyguanosine in LPS-induced microglia activation: suppression of STAT3mediated intercellular adhesion molecule-1 expression. Exp Mol Med. 2006 Aug 31;38(4): 417-27.

38 Kim HS, Ye SK, Cho IH, Jung JE, Kim DH, Choi S, et al. 8-hydroxydeoxyguanosine suppresses NO production and COX-2 activity via Rac1/STATs signaling in LPS-induced brain microglia. Free Radic Biol Med. 2006 Nov 1;41(9):1392-403.

39 Ko SH, Lee JK, Lee HJ, Ye SK, Kim HS, Chung MH. 8-Oxo-2'-deoxyguanosine ameliorates features of metabolic syndrome in obese mice. Biochem Biophys Res Commun. 2014 Jan 10;443(2):610-6.

40 Li J, Shen X. Oxidative stress and adipokine levels were significantly correlated in diabetic patients with hyperglycemic crises. Diabetol Metab Syndr. 2019 Feb 6;11:13.

41 Ott R, Stupin JH, Melchior K, Schellong K, Ziska T, Dudenhausen JW, et al. Alterations of adiponectin gene expression and DNA methylation in adipose tissues and blood cells are associated with gestational diabetes and neonatal outcome. Clin Epigenetics. 2018 Oct 24;10(1):131. 
42 Eleuterio NM, Palei AC, Machado JS, TanusSantos JE, Cavalli RC, Sandrim VC. Role of adiponectin on antioxidant profile: evaluation during healthy and hypertensive disorders of pregnancy. Blood Press. 2016 Aug; 25(4):241-3.

43 Andersson-Hall U, Svedin P, Svensson H, Lönn M, Mallard C, Holmäng A. Longitudinal changes in adipokines and free leptin index during and after pregnancy in women with obesity. Int J Obes. 2019 Sep 24.

44 Suto M, Maeda K, Sato M, Kaji T, Irahara M. Plasma adipokine concentrations in overweight/obese pregnant women: a longitudinal study. Gynecol Endocrinol. 2019 Mar; 35(3):242-6.

45 Serapio S, Ahlsson F, Larsson A, Kunovac Kallak T. Second trimester maternal leptin levels are associated with body mass index and gestational weight gain but not birth weight of the infant. Horm Res Paediatr. 2019 Oct 25;92(2):106-14.

46 Lacroix M, Battista MC, Doyon M, Moreau J, Patenaude J, Guillemette L, et al. Higher maternal leptin levels at second trimester are associated with subsequent greater gestational weight gain in late pregnancy. BMC Pregnancy Childbirth. 2016 Mar 22;16:62.

47 Lappas M, Lim R, Price S, Prendergast LA, Proietto J, Ekinci EI, et al. Exploring the relationship between maternal circulating hormones and gestational weight gain in women without obesity: a cross-sectional study. Int J Womens Health. 2020 Jun 15;12:455-62.
48 Patro-Małysza J, Trojnar M, SkórzyńskaDziduszko KE, Kimber-Trojnar $\dot{Z}$, Darmochwał-Kolarz D, Czuba M, et al. Leptin and ghrelin in excessive gestational weight gain-association between mothers and offspring. Int J Mol Sci. 2019 May 15;20(10): 2398.

49 McClure CK, Catov JM, Ness R, Bodnar LM. Associations between gestational weight gain and BMI, abdominal adiposity, and traditional measures of cardiometabolic risk in mothers 8 year postpartum. Am J Clin Nutr. 2013 Nov;98(5):1218-25.

50 Drolet R, Richard C, Sniderman AD, Mailloux J, Fortier M, Huot C, et al. Hypertrophy and hyperplasia of abdominal adipose tissues in women. Int J Obes. 2008 Feb;32(2):283-91.

51 Chait A, den Hartigh LJ. Adipose tissue distribution, inflammation and its metabolic consequences, including diabetes and cardiovascular disease. Front Cardiovasc Med. 2020;7: 22.

52 Berger S, Polotsky VY. Leptin and leptin resistance in the pathogenesis of obstructive sleep apnea: a possible link to oxidative stress and cardiovascular complications. Oxid Med Cell Longev. 2018 Feb 20;2018:5137947.

53 Martínez-Martínez E, Jurado-López R, Cervantes-Escalera $\mathrm{P}$, Cachofeiro V, Miana $\mathrm{M}$. Leptin, a mediator of cardiac damage associated with obesity. Horm Mol Biol Clin Investig. 2014 Apr;18(1):3-14.

54 Lappas M, Yee K, Permezel M, Rice GE. Release and regulation of leptin, resistin and adiponectin from human placenta, fetal membranes, and maternal adipose tissue and skeletal muscle from normal and gestational diabetes mellitus-complicated pregnancies. J Endocrinol. 2005 Sep;186(3):457-65.
55 Sartori C, Lazzeroni P, Merli S, Patianna VD, Viaroli F, Cirillo F, et al. From placenta to polycystic ovarian syndrome: the role of adipokines. Mediators Inflamm. 2016 Sep;2016: 4981916.

56 Kamigaki M, Sakaue S, Tsujino I, Ohira $\mathrm{H}$, Ikeda $\mathrm{D}$, Itoh $\mathrm{N}$, et al. Oxidative stress provokes atherogenic changes in adipokine gene expression in 3T3-L1 adipocytes. Biochem Biophys Res Commun. 2006 Jan 13;339(2): 624-32.

57 Liu J, Chi N, Chen H, Zhang J, Bian Y, Cui G, et al. Resistin protection against endogenous $\mathrm{A} \beta$ neuronal cytotoxicity from mitochondrial pathway. Brain Res. 2013 Jul 26;1523:77-84.

58 Bo S, Gambino R, Pagani A, Guidi S, Gentile L, Cassader M, et al. Relationships between human serum resistin, inflammatory markers and insulin resistance. Int J Obes. 2005 Nov; 29(11):1315-20.

59 Shang M, Dong X, Hou L. Correlation of adipokines and markers of oxidative stress in women with gestational diabetes mellitus and their newborns. J Obstet Gynaecol Res. 2018 Apr;44(4):637-46.

60 Silberstein T, Hamou B, Cervil S, Barak T, Burg A, Saphier O. Colostrum of preeclamptic women has a high level of polyphenols and better resistance to oxidative stress in comparison to that of healthy women. Oxid Med Cell Longev. 2019 Feb 21;2019:1380605.

61 Burton GJ, Yung HW. Endoplasmic reticulum stress in the pathogenesis of early-onset pre-eclampsia. Pregnancy Hypertens. 2011 Jan;1(1-2):72-8. 